\title{
Indirect effects of species interactions on habitat provisioning
}

\author{
Sally J. Holbrook • Russell J. Schmitt • \\ Andrew J. Brooks
}

Received: 31 August 2010/ Accepted: 7 January 2011/Published online: 28 January 2011

(C) The Author(s) 2011. This article is published with open access at Springerlink.com

\begin{abstract}
Species that shelter in a biogenic habitat can influence their refugia and, in turn, play an essential role in shaping local patterns of biodiversity. Here we explore a positive feedback loop between the provisioning rate of habitat-forming branching corals and their associated fishes and show how interactions between two groups of fishthe planktivorous damselfish and predatory hawkfishaltered the feedback. A field experiment confirmed that skeletal growth of branching coral (genus Pocillopora) increased substantially with increasing numbers (biomass) of resident fishes, likely because they greatly increased the interstitial concentrations of nutrients. Because there is a positive relationship between colony size and number (biomass) of associated fishes (primarily damselfishes in the Family Pomacentridae), a structure-function feedback loop exists in which increasing numbers of damselfish enhance coral growth and larger corals host greater abundances (and species richness) of fish. However, interactions between damselfishes and arc-eye hawkfish, Paracirrhites arcatus, a largely solitary resident, can disrupt this positive feedback loop. Field surveys revealed a marked pattern of fish occupancy related to coral size: Pocillopora colonies of sufficient size to host fish ( $>40 \mathrm{~cm}$ circumference) had
\end{abstract}

Communicated by Øyvind Fiksen.

S. J. Holbrook ( $\varangle)$ · R. J. Schmitt

Department of Ecology, Evolution and Marine Biology,

University of California Santa Barbara, Santa Barbara,

CA 93106, USA

e-mail: holbrook@lifesci.ucsb.edu

S. J. Holbrook · R. J. Schmitt · A. J. Brooks

Coastal Research Center, Marine Science Institute,

University of California Santa Barbara, Santa Barbara,

CA 93106, USA either groups of damselfish or an arc-eye hawkfish; only larger colonies $(>75 \mathrm{~cm})$ were occupied by both the damselfish and hawkfish. Subsequent short- and long-term experiments revealed that on intermediate-sized Pocillopora colonies, arc-eye hawkfish prevented the establishment of damselfish by suppressing their recruitment. The demographic consequences to the host coral were substantial; in a 1-year-long experiment, intermediate-size Pocillopora occupied by hawkfish grew at half the rate of corals that hosted groups of damselfish. These findings indicate that: (1) species which occupy a biogenic habitat can enhance the provisioning rate of their habitat; (2) such positive feedbacks between community structure and ecosystem function can be disrupted by a strong interactor; (3) even substantial consequences on ecosystem processes that arise can be difficult to discern.

Keywords Structure-function feedbacks . Habitat provisioning - Indirect effects - Mutualism · Strong interactors $\cdot$ Refugia $\cdot$ Biodiversity

\section{Introduction}

There is growing appreciation that structural aspects of a community can simultaneously be a cause and a consequence of an ecological rate process (Cardinale et al. 2006). This concept has motivated contemporary interest in understanding reciprocal structure-function feedbacks, together with factors that affect their strength. To date, this perspective has been applied to biodiversity-related questions (Reiss et al. 2009), such as the nature of reciprocal relationships and feedbacks between species diversity and resource availability (Cardinale et al. 2006), disturbance (Hughes et al. 2007), or productivity (Cardinale et al. 
2009). At the landscape scale, the size and availability of essential habitat patches can help shape local patterns of biodiversity (Holbrook et al. 1990; Debinski et al. 2001). It is common for habitats important in supporting biodiversity to be biogenic (e.g., trees, giant kelp, coral). Interactions among species associated with a biogenic habitat have the potential to alter such key ecosystem processes as photosynthesis (King and Caylor 2010) or habitat provisioning (Holbrook et al. 2008), which in turn can have consequences for biodiversity and other important community attributes. For example, anemonefish increase the growth rate of their host anemones (Holbrook and Schmitt 2005), which enhances local biodiversity by enabling the coexistence of inferior space competitors (Schmitt and Holbrook 2003; Holbrook and Schmitt 2004). Positive feedback loops may occur commonly between biogenic habitat and one or more associated species. Such mutualistic relationships range from ants on acacia trees in African savannah (Palmer et al. 2008; King and Caylor 2010) to fishes sheltering on branching corals on tropical reefs (Holbrook et al. 2008).

While mutualisms are vital elements of community structure and ecosystem function (Bronstein 1994; Wilson and Nisbet 1997; Bronstein et al. 2003; Bruno et al. 2003; Stanton 2003; Cahill et al. 2008; Callaway et al. 2008; Gross 2008; Segraves 2008), factors that maintain and break down these reciprocally positive interactions are not fully understood (Palmer et al. 2008). Several different mechanisms can impact the spatial and/or temporal strength of the positive feedbacks between partners. Some are intrinsic to the participating species. For example, one partner can control the strength of the benefit, such as in plant-mycorrhizal interactions. In these instances, plants can selectively interact with a particular mycorrhizal partner that results in a higher benefit (Heath and Tiffin 2009) or differentially reward with nutrients a species that is more beneficial (Bever et al. 2009). Mutualisms also can be interrupted by the action of extrinsic factors, such as abiotic disturbances that reduce the availability of one of the partners. When severe drought resulted in a prolonged lack of flowers on figs (Ficus spp.) in lowland forests of Borneo, there was a corresponding loss of local populations of their species-specific pollinators [fig wasps (Agaonidae); Harrison 2000]. Similarly, mismatch in onset of flowering and in first appearance dates of pollinators due to different phenological responses to climate warming may affect persistence of the interacting species (Hegland et al. 2009).

Biotic interactions, such as predation, herbivory, and interspecific competition, represent another major pathway to the modification of reciprocally positive interactions. One partner can be competitively displaced by a less beneficial one, such as when invasive species of insects pollinate or disperse seeds more poorly than the native species (Dohzono et al. 2008; Rowles and O'Dowd 2009) or disrupt the pollination behavior of the latter (Dohzono et al. 2008; Hansen and Müller 2009). Spiders can negatively affect (both as predators and competitors) hemipterans that are digestive mutualists of the carnivorous plant Roridula (Anderson and Midgley 2002). In contrast, mutualistic interactions are sometimes promoted by other species in the community. Large herbivores help foster the ant-plant mutualism in acacia tress in the African savannah (Palmer et al. 2008), and interactions between symbiotic ants and herbivores can enhance the rate of tree photosynthesis (King and Caylor 2010). Thus, such multispecies interactions are increasingly being recognized as having important consequences not only for the strength and persistence of mutualisms, but also for their effect on key ecosystem processes.

Factors that greatly modify mutualisms can have especially strong effects on biodiversity and ecosystem function when a participant is a biogenic habitat that is foundational to the community. Stony corals on tropical reefs are a case in point; they provide an essential habitat for a wide range of taxa including fishes, crabs, bivalves, shrimps, and sponges. In turn, these species can confer important benefits to the coral, including provision of nutrients (Meyer and Schultz 1985a, b; Mokady et al. 1998; Holbrook et al. 2008), removal of sediments (Stewart et al. 2006), protection from predators (Pratchett et al. 2000; Pratchett 2001), modulation of hydrodynamic conditions (Goldshmid et al. 2004), and enhancement of growth (Meyer and Schultz 1985b; Liberman et al. 1995; Holbrook et al. 2008). Coralassociated fishes and invertebrates obtain benefits from the host, including food, sites for attachment and, very commonly, refuge from predation. We previously explored the positive effects of damselfish on skeletal growth of their host corals (Holbrook et al. 2008). Here we build on those findings by (1) describing the positive structure-function feedback loop between fish abundance and rate of habitat provisioning, and (2) exploring how interactions between groups of sheltering fishes influence the feedback and thus alter the provisioning rate of their habitat.

In lagoons of Moorea, French Polynesia, branching corals in the genus Pocillopora are occupied by a number of species of fish, including planktivorous damselfishes in the Family Pomacentridae that can form large groups and predatory arc-eye hawkfish (Paracirrhites arcatus) that typically occur singly (Holbrook et al. 2008; Kane et al. 2009; Schmitt et al. 2009). The mortality of juvenile yellowtail dascyllus (Pomacentridae) is much higher when they co-occur with arc-eye hawkfish on a coral. Arc-eye hawkfish directly consume the dascyllus and also compete with them for enemy-free space within the coral shelter (Schmitt et al. 2009). Because damselfishes can enhance at least short-term skeletal growth of branching corals 
(Holbrook et al. 2008) and arc-eye hawkfish can reduce survivorship of recently settled damselfish through trophic and competitive interactions (Schmitt et al. 2009), this web of interacting species affords an ideal model system to evaluate the indirect effect of biotic factors in modifying habitat provisioning by altering the strength of reciprocally positive feedbacks.

\section{Methods}

Fieldwork was conducted in lagoons on the north shore of Moorea, French Polynesia $\left(17^{\circ} 30^{\prime} \mathrm{S}, 149^{\circ} 50^{\prime} \mathrm{W}\right)$. A barrier reef surrounds the island and forms lagoons ranging from 0.8 to $1.3 \mathrm{~km}$ in width and water depth of 3-7 m. The lagoon bottom comprises a mosaic of patch reefs, coral rubble, and sand.

The reciprocally positive feedback between damselfish and their coral hosts

\section{Effect of resident fish on coral growth rate}

A field experiment tested the effects of resident fish on growth rates of Pocillopora. This was done by transplanting two small, pre-weighed "nubbins" of Pocillopora eydouxi (hereafter Pocillopora) into each of 20 mature host colonies, half of which (selected at random) had their resident fishes removed. The nubbins, each approximately $3 \mathrm{~cm}$ in length and $1 \mathrm{~cm}$ in diameter, were collected from four donor corals located on the shallow forereef and transported submerged to the laboratory. A small hole was drilled at the base of each nubbin prior to buoyant weighing (Davies 1989), and then the nubbin was secured onto $3 \times 3$-cm squares of plastic using cable ties. Nubbins were kept in the laboratory on outdoor water tables with flowthrough seawater for $24 \mathrm{~h}$ following mounting, then transported (continuously submerged) to the field, assigned at random to treatment, and affixed within the interior of the branching structure of a host coral in a manner that prevented tissue contact between nubbins and the host coral. Host Pocillopora were essentially spherical and had a mean circumference of $140.9 \mathrm{~cm}$ (range 86-190 cm). Each host colony was surrounded by a $1-\mathrm{m}$ in diameter, $1-\mathrm{m}$ tall fence made of galvanized steel mesh $($ size $1 \mathrm{~cm})$. To establish the treatments, all resident fishes were removed from ten randomly selected corals using a mild fish anesthetic at least 2 days prior to the outplanting of nubbins, and tops (1-cm mesh) were immediately placed on these fences to form a fish exclusion cage. Resident fishes, almost all of which were yellowtail dascyllus (Dascyllus flavicaudus), were not removed from the remaining ten corals, and these fences remained open at the top; resident fishes continued to associate with these corals, feeding and sheltering normally. Divers conducted periodic counts of the fishes associated with each host coral throughout the experiment. Shortly after the nubbins were outplanted, one of the corals within the fish exclusion cages was re-colonized by a total of four fishes. To prevent disturbance to the outplanted nubbins, these individuals were not removed.

All coral nubbins were returned to the laboratory and reweighed after 30 days. Nubbin performance was quantified as the increase in the mean skeletal mass (grams) of the two nubbins outplanted within each coral divided by the number of days in the field (hereafter referred to as skeletal growth). We tested the effect of the presence or absence of fish on the mean growth of nubbins with a $t$ test. The relationship between initial skeletal mass of the nubbins and mean daily skeletal growth (grams/day) for the two treatments was explored using analysis of covariance (ANCOVA). We performed a similar experiment during 2005 in the same locality of the lagoon (described in Holbrook et al. 2008). Nubbin growth (g/day) for each of these two sets of experiments was plotted against the number of resident fish on each coral, and differences in the two relationships were tested with ANCOVA. Since size-structure of the resident fish was similar among replicates and years, there was no qualitative difference in the relationships if fish biomass rather than number was used in the analyses.

\section{Patterns of abundance and species richness of fish in Pocillopora}

A survey of 295 colonies of Pocillopora eydouxi in the midlagoon quantified the patterns of abundance of non-cryptic resident fishes. Divers measured the dimensions of each coral (length, width, height, circumference) and counted and estimated the sizes of associated non-cryptic species of fish. Coral colonies were placed into the following size (circumference) classes: $<45(N=40), 45-74(N=47)$, 75-105 $(N=88), \quad 105-134 \quad(N=76), \quad$ and $\geq 135 \mathrm{~cm}$ $(N=44)$. The mean fish species richness, mean number of individuals, and the mean number of early life stages (new settlers and recruits $<1$ month old) were calculated for each group. Differences in these characteristics among corals of different sizes were tested with one-way analysis of variance (ANOVA).

Disruption of the feedback loop

\section{Patterns of damselfish and hawkfish co-occurrence on Pocillopora}

The 295 corals in the survey were assessed with respect to the combination of planktivorous damselfish and predatory species they hosted. Each coral was placed into one of four 
categories: (1) no fish present, (2) damselfish, but not arceye hawkfish (Paracirrhites arcatus) present, (3) arc-eye hawkfish, but not damselfish present, and (4) both hawkfish and damselfish present. The proportion of the corals in the five size categories described above that hosted each combination of species was calculated. In the survey, yellowtail dascyllus and humbug dascyllus (Dascyllus aruanus) were the most prevalent pomacentrids associated with Pocillopora, particularly among fishes that were older juveniles, subadults, and adults (and thus able to provide a significant nutrient benefit to their hosts; Holbrook et al. 2008). The mean abundances of these species on corals with or without hawkfish also present were calculated for three size classes of Pocillopora, namely, circumference of $45-74,75-104$, and $\geq 105 \mathrm{~cm}$. Only corals that hosted fish were used in this analysis.

\section{Mechanisms of hawkfish effects on damselfish abundance and consequences for habitat provisioning}

Using field observations and an experiment, we explored the mechanisms by which arc-eye hawkfish affected the distribution and abundance of damselfish. Patterns of larval settlement of fishes from the plankton to the reef were quantified daily on a group of 18 medium-sized Pocillopora corals that we had re-located to the mid-lagoon. After several months, seven of the corals were colonized naturally by one or two adult arc-eye hawkfish; these colonies were intermingled among 11 others that were not occupied by hawkfish. During the period of observation, there were no other resident fishes on the colonies occupied by hawkfish, while the number of resident fishes on non-hawkfish corals was very low (mean 1.7 fish per coral). Settlement of fish occurs during the night (Holbrook and Schmitt 1997); consequently, divers visited every coral shortly after sunrise daily for 19 consecutive days to verify the presence or absence of hawkfish on the respective coral types and to identify and count the number of newly settled fishes. All newly settled fish were yellowtail dascyllus (Dascyllus favicaudus).

A 1-year-long field experiment tested the effect of resident hawkfish on the establishment of groups of planktivorous damselfishes on Pocillopora. This experiment involved the transplantation of live heads of Pocillopora to a sand plain at a water depth of $3 \mathrm{~m}$ in the middle of the Vaipahu Lagoon, where they would be available as habitat for settling damselfishes (primarily yellowtail dascyllus) during a 12-month period. Twenty corals were collected in water depths of 3-6 m on the offshore barrier reef, transported in seawater, and glued to cinder blocks using Z-Spar Splash Zone Compound (Kop-coat, Pittsburg, PA). Corals were spaced a minimum of $5 \mathrm{~m}$ apart, with greater distances used between adjacent hawkfish and no hawkfish colonies to reduce the potential for movement of fish between treatments. The 20 outplanted corals were measured (length, width, height, circumference) and averaged $66.8 \mathrm{~cm}$ in circumference (range $57-76 \mathrm{~cm}$ ). At the start of the experiment, all fish were removed from the corals; ten arc-eye hawkfish were captured by divers using hand nets and one hawkfish was outplanted to each of ten corals. The other ten corals did not receive hawkfish. We did not manipulate the pairs of crabs (Trapezia rufopunctata) that occurred in each coral. Mean circumference was not different for the groups of corals in the two treatments $(t=0.61,2 d f, P>0.60)$. Divers visited the corals every 3 months for 1 year. At each survey, the presence of hawkfish was verified on the corals, and all fishes were identified and counted and their body size (total length) estimated. At the final survey, each coral was remeasured so that change in size (and thus habitat provided to fish) during the year could be estimated. Initial and final volumes were calculated for each colony as an ellipsoid, and the change in volume was estimated as $[\log ($ final volume $)-\log$ (initial volume)]. Difference in growth between corals that hosted a hawkfish and those that did not was tested by ANOVA.

Fish excrete nitrogenous waste, principally ammonium, which is a mechanism that has been hypothesized as a cause for the enhancement of growth of corals (Meyer and Schultz 1985a, b; Holbrook et al. 2008) and tropical anemones (Holbrook and Schmitt 2005; Roopin et al. 2008; Roopin and Chadwick 2009). We undertook laboratory studies to estimate ammonium production by species of fishes that associate with Pocillopora (also see Holbrook et al. 2008). On Moorea, the most abundant residents in Pocillopora in mid-lagoon areas are damselfishes [yellowtail dascyllus (Dascyllus flavicaudus), bluegreen chromis (Chromis viridis), and humbug dascyllus (Dascyllus aruanus) (Holbrook et al. 2008)]; arc-eye hawkfish (Paracirrhites arcatus) also are prevalent. In the laboratory, a length-biomass relationship for each species was established by damp weighing measured individuals to the nearest thousandth of a gram within $1 \mathrm{~h}$ of collection from the field. To estimate the production of ammonium as a function of fish biomass, individuals of each species representing a range of body sizes were captured in the field and maintained in a 50-1 aquarium supplied with flowthrough seawater. Because previous studies have shown that excretion rates of ammonium by fish can vary widely over the first $24 \mathrm{~h}$ subsequent to the last meal (Roopin et al. 2008), fish were held in the laboratory without feeding for $24 \mathrm{~h}$ before they were added individually to closed, aerated 15-1 aquaria maintained under natural daylight conditions on shaded, outdoor water tables and immersed in flowthrough seawater to control fluctuations in water temperature. An initial 20-ml sample of water was collected from each aquarium containing fish into new $25-\mathrm{ml}$ plastic vials at the beginning and then every $4 \mathrm{~h}$ over a period of $24 \mathrm{~h}$. 
Additional 20-ml water samples were collected simultaneously from two additional aquaria lacking fish that served as controls. All water samples were immediately frozen and stored at $-80^{\circ} \mathrm{C}$ for no longer than 2 weeks before being returned on dry ice to the Marine Science Institute's Analytical Laboratory on the campus of the University of California, Santa Barbara and analyzed using a Lachat QuikChem 8000 flow injection analyzer (Lachat Instruments Div., Zellweger Analytics, Poole, Dorset, UK).

Rates of ammonium production by individual species were estimated from the slopes of the linear relationship obtained by regressing measured ammonium concentration ( $\mu$ moles) against time (hours). To obtain size-specific production rates, we plotted the size (length or mass) of each individual against its estimated rate of ammonium production and performed best fit relationships between fish body size and production rate separately for arc-eye hawkfish and each damselfish species ( $r^{2}$ values ranged from 0.72 to 0.85 ; all $P<0.01)$. These relationships were used with sizespecific estimates of damselfish and arc-eye hawkfish abundances on the corals in the year-long field experiment to assess their relative contributions to enriching the local flux of ammonium on a coral. The estimate was made using data gathered at the final (1 year) survey; one species (Dascyllus flavicaudus) constituted 98\% (by numbers and biomass) of all damselfish present. Ammonia production for each fish observed in the survey was estimated using the species-specific best fit relationship between a fish's body size and its production. The production on each coral was obtained by summing the size-specific production estimates for all fishes observed on that host coral, and this variate was used to calculate the mean [ \pm standard error (SE)] production for the corals in each treatment (with or without hawkfish) using corals as replicates.

Data analyses

All statistical analyses were performed using SAS ver. 9.1 (SAS Institute 2003). Tests for normality and homogeneity of variances were performed in accordance with standard statistical practices, and when necessary, data were transformed prior to analyses.

\section{Results}

The reciprocally positive feedback between damselfish and their coral hosts

\section{Effect of resident fish on coral growth rate}

In the 2008 experiment, Pocillopora colonies with resident fish averaged $25.6 \pm 2.74$ fish (mean $\pm 1 \mathrm{SE}$ ), which is significantly more than those in the fish exclusion treatment (0.4 $\pm 0.4 \mathrm{fish} ; t_{9}=9.10, P<0.001$ assuming unequal variances). Of the resident fish, $90 \%$ were damselfish, and of these, $70 \%$ were yellowtail dascyllus. There was no significant difference in mean initial weight of the coral nubbins assigned to the two treatments $\left(t_{38}=0.17\right.$, $P=0.86$ using pooled variances), and all nubbins survived the 30-day outplant period without showing any signs of bleaching or tissue damage. Daily growth of coral nubbins was, on average, $24 \%$ greater in the presence than absence of damselfish (mean with fish $0.0171 \mathrm{~g} /$ day, mean without fish $0.0138 \mathrm{~g} /$ day), a difference that was statistically significant $\left(t_{18}=2.39, P<0.03\right.$ using pooled variances $)$. Although the initial mean skeletal mass of nubbins assigned to the two treatments did not differ, there was some variation in sizes. We explored the relationship between initial skeletal mass and subsequent daily growth for the two treatments with ANCOVA and found a significant and positive relationship between initial nubbin mass and the daily increase in mass $\left(F_{2,37}=11.96\right.$, $P<0.001)$; this relationship was the same regardless of treatment (fish present or absent; non-significant interaction term, $F_{3,36}=0.25, P=0.62$ ). Coral nubbins outplanted into host corals containing fish exhibited significantly higher average daily increases in mass than those nubbins that were outplanted into host corals that lacked fish $\left(F_{2,37}=11.90, P<0.001\right)$.

The average effect of damselfish on coral growth in the 2008 experiment was about half that we measured in our 2005 experiment (Holbrook et al. 2008), but this apparent difference in effect size was related to natural differences between the trials in the average abundance of damselfish on colonies. Indeed, nubbin growth was positively related to the abundance of fish on the host coral in the same way in both the 2005 and 2008 trials (Fig. 1; ANCOVA $\left.F_{1,36}=11.43, P<0.001\right)$, and neither the main effect of trial (year of experiment) nor the interaction of trial and fish abundance was significant (both $P>0.45$ ).

\section{Patterns of abundance and species richness of fish in Pocillopora}

Field surveys revealed that Pocillopora rarely hosted fish until the coral reached a size of $45 \mathrm{~cm}$ in circumference (Fig. 2). Once past this threshold, the abundance and species richness of fish rose with colony size, with the largest corals providing the most fish habitat. Species richness per coral increased across the range of coral sizes sampled (Fig. 2a; ANOVA $F_{4,290}=95.81, P<0.0001$ ) as did the total number of fish on a coral (Fig. 2b; ANOVA $F_{4,290}=$ 10.50, $P<0.0001), 97 \%$ of which were damselfish. More fish recruited from the plankton onto larger than smaller corals (Fig. 2c; ANOVA $F_{4,290}=4.09, P<0.003$ ). 


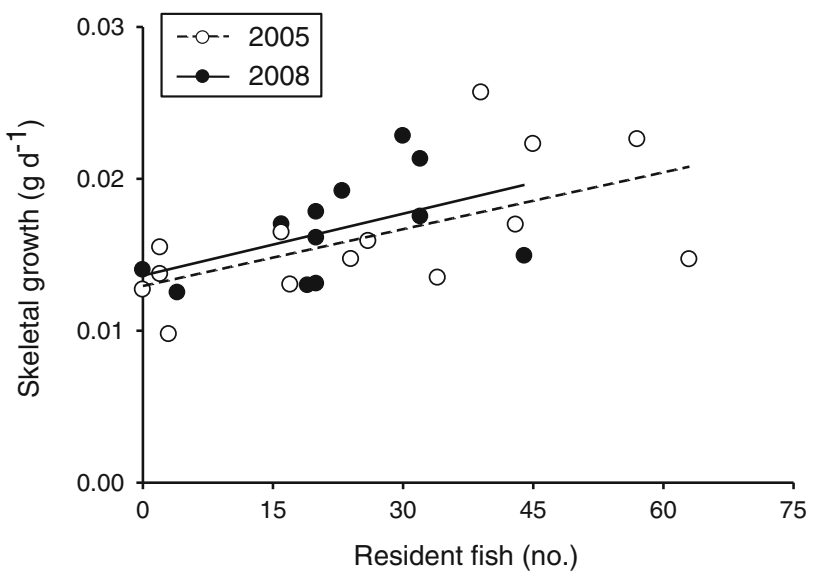

Fig. 1 Relationship between abundance of coral-dwelling fishes (primarily Dascyllus flavicaudus) and skeletal growth of Pocillopora coral. Data are changes in mass of coral nubbins outplanted on host colonies in short-term field experiments conducted in Moorea, French Polynesia in 2005 (open circles) and 2008 (closed circles)

Disruption of the feedback loop

\section{Pattern of damselfish and hawkfish co-occurrence on Pocillopora}

Field surveys revealed that, for coral large enough to host fish, colonies of the same size frequently would be occupied by either damselfish or an arc-eye hawkfish (Fig. 3). The pattern was most striking for colonies in the smallest category of corals that could host fish (circumference 45-74 cm): when occupied, these small corals supported one fish group or the other and almost never both (Fig. 3). The majority of medium-sized (circumference 75-104 cm) Pocillopora also hosted only a hawkfish or damselfishes, but not both. By contrast, the two groups of fishes cooccurred commonly on larger corals (circumference $\geq 105 \mathrm{~cm}$ ) (Fig. 3). Overall, the proportion of corals hosting both hawkfish and damselfish increased with colony size. Arc-eye hawkfish tended to be solitary and rarely occurred in pairs; a single specimen was observed on $75 \%$ of hawkfish-occupied corals, and the mean number of hawkfish per occupied coral was 1.3.

The pattern of damselfish abundance in the presence relative to absence of hawkfish also varied with size of the coral host (Fig. 4). There were substantially fewer damselfish individuals in the presence of hawkfish on small corals and medium-sized corals, but no difference in damselfish numbers in the presence compared to absence of hawkfish on large corals (Fig. 4; coral size category $\times$ hawkfish category interaction: $\left.F_{2,219}=8.02 ; P<0.001\right)$.
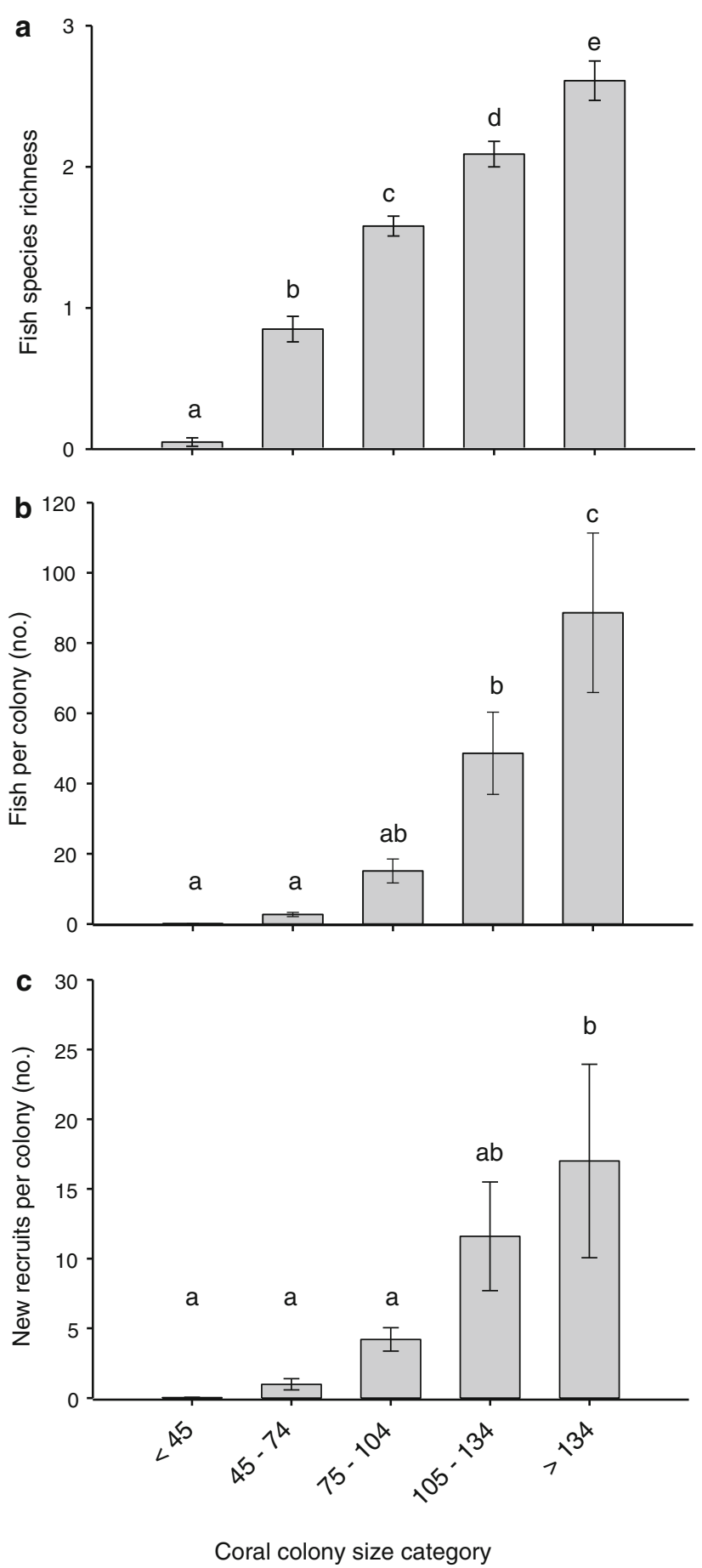

Fig. 2 Relationships between size [mean \pm standard error (SE)] of Pocillopora host corals and species richness of resident fishes (a), number of resident fishes (b), and number of newly settled fishes (c). $N=40,47,88,76$, and 44 from smallest to largest colony size category, respectively. Size categories are based on colony circumferences $(\mathrm{cm})$. Different letters indicate statistical differences among categories in the analysis of variance (ANOVA) at $P<0.05$ 


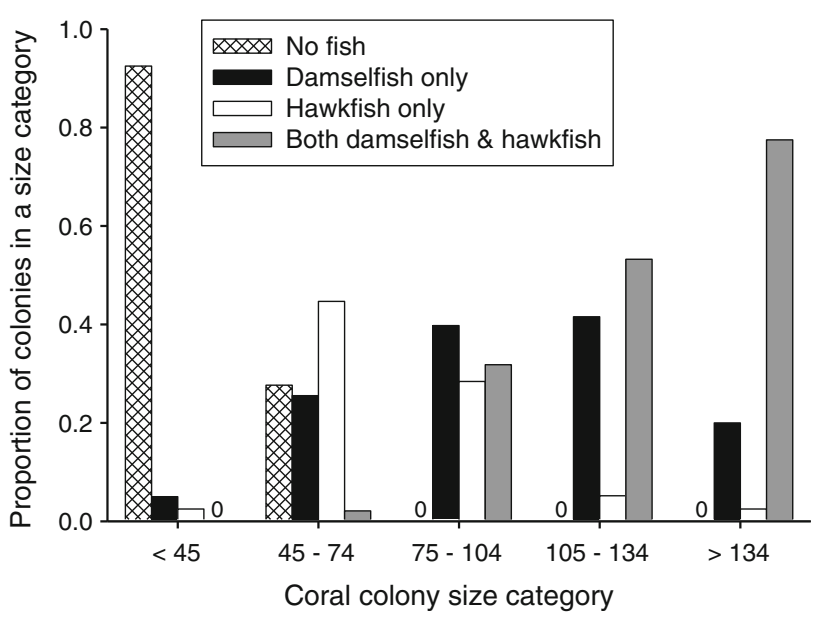

Fig. 3 Colony size-specific patterns of occurrence of two fish groups on Pocillopora (see Fig. 2 legend for sample sizes). Shown are the proportion of colonies in each size category that hosted no fish at all, damselfish only, hawkfish only, and both damselfish and hawkfish, respectively

\section{Mechanisms of hawkfish effects on damselfish abundance and consequences for habitat provisioning}

The presence of hawkfish drastically reduced successful settlement of larval damselfish to Pocillopora. Over the 19-day settlement period, divers observed an average of 0.3 damselfish settlers per coral on colonies that hosted an arceye hawkfish, whereas neighboring colonies (of the same size) that lacked hawkfish averaged greater than ten settlers over the same period (Fig. 5a; $t=4.88, P<0.003$ ). Divers visited the corals early each morning and verified the presence of settlers from the previous night. We do not

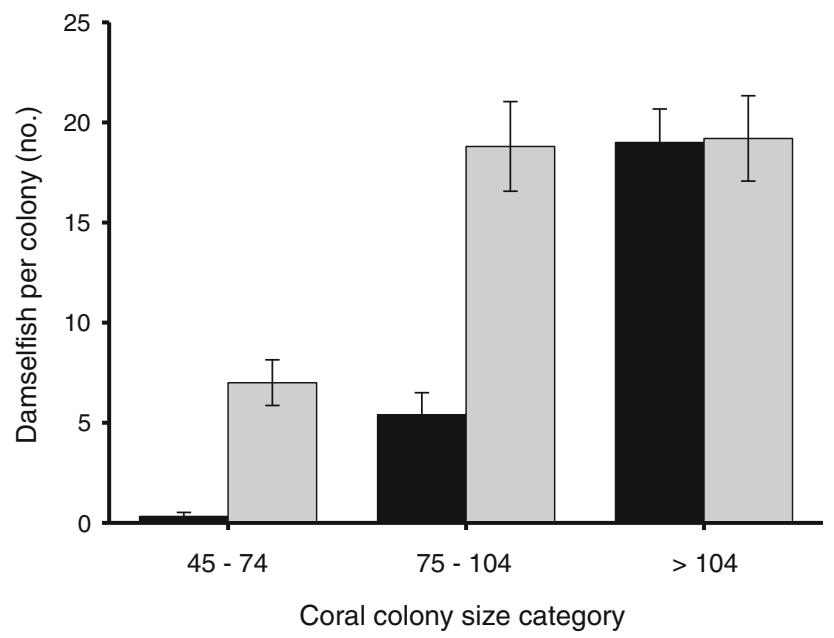

Fig. 4 Patterns of abundance of damselfish (mean \pm 1 SE, $n=225$ ) on corals of different sizes in the presence (black bars) or absence (grey bars) of arc-eye hawkfish. Corals $>104 \mathrm{~cm}$ in circumference include all corals in the two largest size categories of Figs. 2 and 3 know if potential settlers were able to detect hawkfishoccupied corals and avoid settling on them, or if they settled on such corals in the night and were consumed before the diver counts were made. Our 1-year-long field experiment revealed that suppression of successful recruitment of young damselfish by arc-eye hawkfish prevented the formation of damselfish colonies on mediumsized Pocillopora. After 1 year, none of the experimental corals that hosted a hawkfish was occupied by even a single damselfish individual, while colonies that lacked hawkfish averaged 12 juveniles and subadults (Fig. 5b). The difference in composition of the fish community that developed between the two groups of experimental corals had a marked effect on the long-term growth rate of the habitat. After 1 year, the increase in volume of corals colonized by damselfish was about twice that of corals that were occupied by hawkfish (Fig. $5 \mathrm{c}$; one-tailed $t$ test: $t_{18}=2.04$; $P<0.03$ ).

The results of the field experiments demonstrate that damselfish enhance the rate of production of their coral habitat. One hypothesized mechanism is that resident fish enhance the flux of nutrients essential to coral growth on a highly localized scale; ammonium is the primary nitrogenous waste excreted by fishes. Based on coupling our laboratory-based estimates of size (biomass)-specific rates of ammonium production by damselfishes with size-specific abundance estimates of damselfish groups on experimental corals, we estimate that the average rate of ammonium excreted by a damselfish group was approximately $0.98 \pm 0.18$ (mean \pm 1 SE) $\mu$ moles $1^{-1} \mathrm{~h}^{-1}$ when the long-term experiment was terminated. By contrast, we calculate that, on average, an arc-eye hawkfish excretes approximately $0.41 \pm 0.03 \mu$ moles $1^{-1} \mathrm{~h}^{-1}$.

\section{Discussion}

In our model system, the local abundance of fish that shelter on a host coral was simultaneously a cause and a consequence of the provisioning rate of its biogenic habitat. The number, biomass, and species richness of fishes that reside among the branches of Pocilloporid corals generally scale positively with colony size because larger colonies provide more habitat space. In a previous long-term colonization experiment in which the amount of initially unoccupied branching coral was manipulated, we found that local populations of damselfishes generally are strongly habitat-limited at our study locality (Holbrook et al. 2000; Schmitt and Holbrook 2000), with both larval recruitment and per capita survivorship suppressed greatly by increasing densities of resident damselfish on a host coral (Schmitt and Holbrook 1999a, b; 2000; Holbrook and Schmitt 2002, 2003). Hence, factors that enhance the 

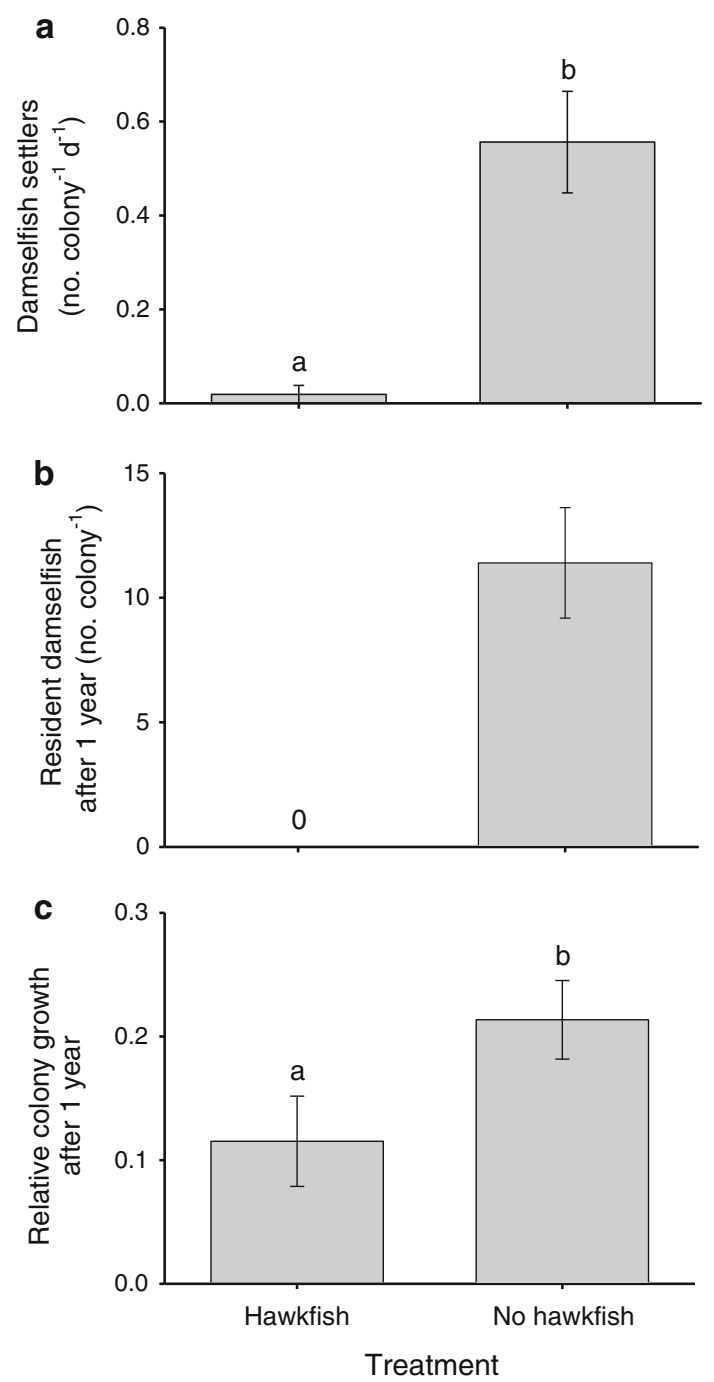

Fig. 5 Results of field experiments to test the effects of arc-eye hawkfish on the positive feedback loop between damselfish and their host corals. Shown are: a numbers of settling damselfish on mediumsized corals (75-104 colony size category) in the presence or absence of hawkfish, b number of resident damselfish after 12 months of colonization to experimental corals (initially in the $45-74 \mathrm{~cm}$ size category and devoid of damselfish) that did or did not receive an outplanted hawkfish, c relative change in volume of experimental corals after 12 months. Data are given as mean \pm 1 SE. Different letters indicate statistical differences between hawkfish treatments as indicated by ANOVA at $P<0.05$

growth of the coral host have cascading effects on the abundance and richness of the associated fishes. The results of field experiments presented here confirm previous observations and short-term manipulations (e.g., Meyer and Schultz 1985a, b; Holbrook et al. 2008) which indicated that the rate of coral skeletal growth scales positively with the abundance (biomass) of sheltering fish. While the precise mechanism for the positive effect of fish on coral growth is not conclusively known, it appears to be related to local nutrient enrichment via excretion of nitrogenous wastes, primarily ammonium, by fishes, which has been hypothesized as a cause for enhanced demographic performance of corals (Meyer and Schultz 1985a, b; Liberman et al. 1995; Holbrook et al. 2008) and tropical anemones (Porat and Chadwick-Furman 2004, 2005; Holbrook and Schmitt 2005; Roopin et al. 2008; Roopin and Chadwick 2009).

Whatever the mechanism underlying the effect of fish on coral, a reciprocally positive structure-function feedback loop exists between fishes and their host-the coral provides refuge space for fishes, which in turn enhance the production of additional habitat space. The strength of the feedback is influenced by the abundance of resident fishes, with planktivorous damselfishes providing the greatest benefit to their host because they can form large resident social groups on a colony (Figs. 1, 2; Holbrook et al. 2008). Arc-eye hawkfish also are frequent inhabitants of Pocillopora colonies, although it is relatively uncommon for more than a single individual arc-eye hawkfish to occur on a host coral due to the social structure of this species, which involves the formation of small $(<8$ individuals) territorial harems on spatial scales much larger than a colony of branching coral (Kane et al. 2009). Because an averaged-sized arc-eye hawkfish and an adult damselfish have about the same biomass (and produce ammonium at roughly the same rate), the difference in social systems between these fish groups determines their relative value as a mutualist partner to the coral. Interactions between hawkfish and damselfish greatly reduce the abundance and biomass of sheltering fish on a colony and, as a consequence, greatly weaken the positive influence of fish on the growth rate of their host. This is particularly the case for small- to medium-sized colonies where the presence of an arc-eye hawkfish can keep a coral host entirely devoid of damselfish by suppressing larval recruitment and subsequent survivorship. This interaction has profound implications for the dynamics of the coral as the mortality rate of a colony generally scales inversely to its size (Hughes and Connell 1987). It also has substantial community-level consequences because larger coral colonies support a greater diversity of species (Holbrook et al. 2002).

Understanding factors that influence the strength of positive feedbacks between partners in a mutualistic interaction is essential for predicting its demographic, population, and community consequences. An increasing number of studies have documented spatial and/or temporal variation in the reward quality of mutualisms, and many of these have identified interactions with other species as an underlying cause (Bronstein et al. 2003). Invasive species can disrupt existing mutualisms by reducing the abundance of native partners or by forming new associations with native and/or introduced species (Liu and Pemberton 2009; Rowles and O’Dowd 2009). However, 
interactions with co-mutualist and/or antagonist species within intact communities also can alter benefits accrued by the main partners in a mutualism (Bronstein et al. 2003). In the system we studied, there were dramatic differences in the benefit conferred on the host coral by the two groups of mutualist fish; after 1 year branching corals that were colonized by damselfish grew twice as much as those that hosted a hawkfish. Despite the differences in reward they offer to their coral hosts, both damselfish and hawkfish gain protection benefits from the association, as they shelter in the coral by night and, when threatened by predators, during the day (Holbrook and Schmitt 2002; Schmitt et al. 2009). Protection benefits gained by fish from their host corals and other cnidarians (e.g., sea anemones) are well known, and indeed numerous taxa cannot survive apart from their host species (Fautin 1991; Fautin and Allen 1997; Holbrook and Schmitt 2002; Munday 2004; Thompson et al. 2006; Ollerton et al. 2007). The protection mutualism we studied lies at the heart of a network of interacting species with intraguild predation, where both direct and indirect interactions arise from the use of a structural refuge (Schmitt et al. 2009). In this situation, mortality of the shared prey (damselfish) is higher in the presence of two intraguild prey [arc-eye hawkfish and redspotted coral crabs (Trapezia rufopunctata)], and all three are vulnerable to a suite of mobile intraguild predators that attack from the exterior of the coral (Holbrook and Schmitt 2002). Damselfishes suffer high mortality during and just after settlement, mainly arising from competition for refuge space, rather than direct consumption, by the intraguild prey (Schmitt and Holbrook 2007; Schmitt et al. 2009). In this study, damselfish were not able to become established on medium-sized corals that supported arc-eye hawkfish during a 1-year-long experiment. Only when branching corals reach a sufficiently large size are hawkfish unable to defend them against invading groups of older stage damselfish. Thus, hawkfish are able to disrupt the very strong positive feedback loop between damselfishes and host corals during a substantial portion of the life of the host Pocilloporid coral.

A number of mutualisms have been identified in which one partner can control the strength of the benefit afforded to the other, or even exert choice among mutualist partners. For example, host plants can preferentially allocate photosynthate to (Bever et al. 2009), or selectively interact with, the most beneficial arbuscular mycorrhizal fungal symbiont (Heath and Tiffin 2009). Although it seems obvious that it is more beneficial for branching coral hosts to partner with damselfish, we do not know the degree to which partner choice mechanisms could be operating in the system. It is unlikely that a host coral would be able to actively choose one over another of the fish mutualists. However, corals exhibit considerable morphological variation, often in response to physical factors, such as light and water movement (Kaandorp 1999). Arc-eye hawkfish prefer to occupy large colonies with an open branching morphology (Kane et al. 2009), and even young hawkfish might respond to aspects of colony architecture during habitat selection. On Moorea, arc-eye hawkfish and damselfish-occupied branching corals are intermingled in the same reef habitats, and we do not exclude the possibility that patterns of occupancy are determined merely by chance encounters between fish and coral hosts as they become available (due to death of previous residents or growth of a small coral to the threshold size for fish occupancy).

A number of potential pathways have been identified by which direct and indirect interspecific interactions can affect the existence and strength of mutualisms (Cahill et al. 2008; Palmer et al. 2008; Rowles and O'Dowd 2009). In our system, biotic interactions between mutualists of different value to their shared partner altered the strength of positive feedbacks in a structure-function feedback loop. Our findings illustrate how species interactions can have profound community and ecosystem-level consequences when embedded in a system with reciprocal feedbacks.

Acknowledgments We thank K. Seydel and M. Schmitt for assistance in the field. We gratefully acknowledge the support of the National Science Foundation (OCE 04-17412, OCE 10-26851) and the Gordon and Betty Moore Foundation. This is a contribution of the Moorea Coral Reef (MCR) LTER Site and of the U.C. Berkeley Gump Research Station.

Open Access This article is distributed under the terms of the Creative Commons Attribution Noncommercial License which permits any noncommercial use, distribution, and reproduction in any medium, provided the original author(s) and source are credited.

\section{References}

Anderson B, Midgley JJ (2002) It takes two to tango but three is a tangle: mutualists and cheaters on the carnivorous plant Roridula. Oecologia 2002:369-373

Bever JD, Richardson SC, Lawrence BM, Holmes J, Watson M (2009) Preferential allocation to beneficial symbiont with spatial structure maintains mycorrhizal mutualism. Ecol Lett 12:13-21

Bronstein JL (1994) Our current understanding of mutualism. Q Rev Biol 69:31-51

Bronstein JL, Wilson WG, Morris WF (2003) Ecological dynamics of mutualist/antagonist communities. Am Nat 162:S24-S39

Bruno JF, Stachowicz JJ, Bertness MD (2003) Inclusion of facilitation into ecological theory. Trends Ecol Evol 18:119-125

Cahill JF Jr, Elle E, Smith GR, Shore BH (2008) Disruption of a belowground mutualism alters interactions between plants and their floral visitors. Ecology 89:1791-1801

Callaway RM, Cipollini D, Barto K, Thelen GC, Hallett SG, Prati D, Stinson K, Klironomos J (2008) Novel weapons: invasive plant suppresses fungal mutualists in America but not in its native Europe. Ecology 89:1043-1055 
Cardinale BJ, Weis JJ, Forbes AE, Tilmon KJ, Ives AR (2006) Biodiversity as both a cause and consequence of resource availability: a study of reciprocal causality in a predator-prey system. J Anim Ecol 75:497-505

Cardinale BJ, Bennett BM, Nelson CE, Gross K (2009) Does productivity drive diversity or vise versa? A test of the multivariate productivity-diversity hypothesis in streams. Ecology 90:1227-1241

Davies PS (1989) Short-term growth measurements of corals using an accurate buoyant weighing technique. Mar Biol 101:389-395

Debinski DM, Ray C, Saveraid EH (2001) Species diversity and the scale of the landscape mosaic: do scales of movement and patch size affect diversity? Biol Conserv 98:179-190

Dohzono I, Kunitake YK, Yokoyama J, Goka K (2008) Alien bumble bee affects native plant reproduction through interactions with native bumble bees. Ecology 89:3082-3092

Fautin D (1991) The anemonefish symbiosis: what is known and what is not. Symbiosis 10:23-46

Fautin D, Allen GR (1997) Anemone fishes and their host sea anemones. Western Australian Museum, Perth

Goldshmid R, Holzman R, Weihs D, Genin A (2004) Aeration of corals by sleep-swimming fish. Limnol Oceanogr 49:1832-1839

Gross K (2008) Positive interactions among competitors can produce species-rich communities. Ecol Lett 11:929-936

Hansen DM, Müller CB (2009) Invasive ants disrupt gecko pollination and seed dispersal of the endangered plant Roussea simplex in Mauritius. Biotropica 41:202-208

Harrison RD (2000) Repercussions of El Niño: drought causes extinction and the breakdown of mutualism in Borneo. Proc R Soc Lond B 267:911-915

Heath KD, Tiffin P (2009) Stabilizing mechanisms in a legumerhizobium mutualism. Evolution 63:652-662

Hegland SJ, Nielson A, Lázaro A, Bjerknes A-L, Totland Ø (2009) How does climate warming affect plant-pollinator interactions? Ecol Lett 12:184-195

Holbrook SJ, Schmitt RJ (1997) Settlement patterns and process in a coral reef damselfish: in situ nocturnal observations using infrared video. Proc 8th Int Coral Reef Symp 2:1143-1148

Holbrook SJ, Schmitt RJ (2002) Competition for shelter space causes density-dependent predation mortality in damselfishes. Ecology 83:2855-2868

Holbrook SJ, Schmitt RJ (2003) Spatial and temporal variation in mortality of newly settled damselfish: patterns, causes and covariation with settlement. Oecologia 135:532-541

Holbrook SJ, Schmitt RJ (2004) Population dynamics of a damselfish: effects of a competitor that also is an indirect mutualist. Ecology 85:979-985

Holbrook SJ, Schmitt RJ (2005) Growth, reproduction and survival of a tropical sea anemone (Actiniaria): benefits of hosting anemonefish. Coral Reefs 24:67-73

Holbrook SJ, Schmitt RJ, Ambrose RF (1990) Biogenic habitat structure and characteristics of temperate reef fish assemblages. Austral Ecol 15:489-503

Holbrook SJ, Forrester GE, Schmitt RJ (2000) Spatial patterns in abundance of a damselfish reflect availability of suitable habitat. Oecologia 122:109-120

Holbrook SJ, Brooks AJ, Schmitt RJ (2002) Predictability of fish assemblages on coral patch reefs. Mar Freshw Res 53:181-188

Holbrook SJ, Brooks AJ, Schmitt RJ, Stewart HL (2008) Effects of sheltering fish on growth of their host corals. Mar Biol 155:521-530

Hughes TP, Connell JH (1987) Population dynamics based on size or age? A reef-coral analysis. Am Nat 129:818-829

Hughes AR, Byrnes JE, Kimbro DL, Stachowicz JJ (2007) Reciprocal relationships and potential feedbacks between biodiversity and disturbance. Ecol Lett 10:849-864
Kaandorp JA (1999) Morphological analysis of growth forms of branching marine sessile organisms along environmental gradients. Mar Biol 134:295-306

Kane C, Brooks AJ, Holbrook SJ, Schmitt RJ (2009) The role of microhabitat preference and social organization in determining the spatial distribution of a coral reef fish. Environ Biol Fishes 84:1-10

King EG, Caylor KK (2010) Herbivores and mutualistic ants interact to modify tree photosynthesis. New Phytol 187:17-21

Liberman T, Genin A, Loya Y (1995) Effects on growth and reproduction of the coral Stylophora pistillata by the mutualistic damselfish Dascyllus marginatus. Mar Biol 121:741-746

Liu H, Pemberton RW (2009) Solitary invasive orchid bee outperforms co-occurring native bees to promote fruit set of an invasive Solanum. Oecologia 159:515-525

Meyer JL, Schultz ET (1985a) Migrating haemulid fishes as a source of nutrients and organic matter on coral reefs. Limnol Oceanogr 30:146-156

Meyer JL, Schultz ET (1985b) Tissue condition and growth rate of coral associated with schooling fish. Limnol Oceanogr 30:157-166

Mokady O, Loya Y, Lazar B (1998) Ammonium contribution from boring bivalves to their coral host-a mutualistic symbiosis? Mar Ecol Prog Ser 169:295-301

Munday PL (2004) Habitat loss, resource specialization, and extinction on coral reefs. Global Change Biol 10:1642-1647

Ollerton J, McCollin D, Fautin DG, Allen GR (2007) Finding NEMO: nestedness engendered by mutualistic organization in anemonefish and their hosts. Proc R Soc Lond B 274:591-598

Palmer TM, Stanton ML, Young TP, Goheen JR, Pringle RM, Karban R (2008) Breakdown of an ant-plant mutualism follows the loss of large herbivores from an African savanna. Science 319:192-195

Porat D, Chadwick-Furman NE (2004) Effects of anemonefish on giant sea anemones: expansion behavior, growth, and survival. Hydrobiologia 530/531:513-520

Porat D, Chadwick-Furman NE (2005) Effects of anemonefish on giant sea anemones: ammonium uptake, zooxanthellae content and tissue regeneration. Mar Freshw Behav Physiol 38:43-51

Pratchett MS (2001) Influence of coral symbionts on feeding preferences of crown-of-thorns starfish Acanthaster planci in the western Pacific. Mar Ecol Prog Ser 214:111-119

Pratchett MS, Vytopil E, Parks P (2000) Coral crabs influence the feeding patterns of crown-of-thorns starfish. Coral Reefs 19:36

Reiss J, Bridle JR, Montoya JM, Woodward G (2009) Emerging horizons in biodiversity and ecosystem functioning research. Trends Ecol Evol 24:505-514

Roopin M, Chadwick NE (2009) Benefits to host sea anemones from ammonia contributions of resident anemonefish. J Exp Mar Biol Ecol 370:27-34

Roopin M, Henry RP, Chadwick NE (2008) Nutrient transfer in a marine mutualism: patterns of ammonia excretion by anemonefish and uptake by giant sea anemones. Mar Biol 154:547556

Rowles AD, O'Dowd DJ (2009) New mutualism for old: indirect disruption and direct facilitation of seed dispersal following Argentine ant invasion. Oecologia 158:709-716

SAS Institute (2003) SAS version 9.1. SAS Institute, Cary

Schmitt RJ, Holbrook SJ (1999a) Settlement and recruitment of three damselfish species: larval delivery and competition for shelter space. Oecologia 118:76-86

Schmitt RJ, Holbrook SJ (1999b) Early mortality of juvenile damselfish: implications for assessing the processes that determine patterns of abundance. Ecology 80:35-50

Schmitt RJ, Holbrook SJ (2000) Habitat-limited recruitment of coral reef damselfish. Ecology 81:3479-3494 
Schmitt RJ, Holbrook SJ (2003) Mutualism can mediate competition and promote coexistence. Ecol Lett 6:898-902

Schmitt RJ, Holbrook SJ (2007) The scale and cause of spatial heterogeneity in the strength of temporal density dependence. Ecology 88:1241-1249

Schmitt RJ, Holbrook SJ, Brooks AJ, Lape JCP (2009) Intraguild predation and competition for enemy-free space: distinguishing multiple predator from competitor effects in a structured habitat. Ecology 90:2434-2443

Segraves KA (2008) Florivores limit cost of mutualism in the yuccayucca moth association. Ecology 89:3215-3221
Stanton ML (2003) Interacting guilds: moving beyond the pairwise perspective on mutualisms. Am Nat 162:S1-S23

Stewart HL, Holbrook SJ, Schmitt RJ, Brooks AJ (2006) Symbiotic crabs maintain coral health by clearing sediments. Coral Reefs 25:609-615

Thompson AR, Nisbet RM, Schmitt RJ (2006) Dynamics of mutualist populations that are demographically open. J Anim Ecol 75:1239-1251

Wilson WG, Nisbet RM (1997) Cooperation and competition along smooth environmental gradients. Ecology 78:2004-2017 